\title{
CORRECTION
}

View Article Online

View Journal | View Issue

Check for updates

Cite this: J. Mater. Chem. C, 2018, 6,668

DOI: $10.1039 / c 7 t c 90204 b$

rsc.li/materials-c

\section{Correction: Bright and efficient light-emitting diodes based on MA/Cs double cation perovskite nanocrystals}

\author{
Bing $\mathrm{Xu}^{\mathrm{ab}}$ Weigao Wang, ${ }^{\mathrm{a}}$ Xiaoli Zhang, ${ }^{\mathrm{ab}}$ Wanyu Cao, ${ }^{\mathrm{c}}$ Dan $\mathrm{Wu},{ }^{\mathrm{d}}$ Sheng Liu, ${ }^{\mathrm{b}}$ \\ Haitao Dai, ${ }^{c}$ Shuming Chen, ${ }^{\star a}$ Kai Wang ${ }^{\star a}$ and Xiaowei Sun ${ }^{\star a}$
}

Correction for 'Bright and efficient light-emitting diodes based on MA/Cs double cation perovskite nanocrystals' by Bing Xu et al., J. Mater. Chem. C, 2017, 5, 6123-6128.

The authors regret a mistake in reporting the solvent used in the fabrication of $\mathrm{MAPbBr}_{3}$ in the Experimental section.

The sentence "For the $\mathrm{MAPbBr}_{3}$ synthesis, a $200 \mu \mathrm{L}$ solution containing $0.1 \mathrm{mmol}^{\mathrm{m}} \mathrm{PbBr}_{2}, 0.16 \mathrm{mmol}$ of $\mathrm{MABr}, 20 \mu \mathrm{L}$ of oleylamine and $500 \mu \mathrm{L}$ of oleic acid in dimethylformamide were added to $10 \mathrm{~mL}$ acetone at room temperature to produce a colloidal solution." should read "For the $\mathrm{MAPbBr}_{3}$ synthesis, a $200 \mu \mathrm{L}$ solution containing $0.1 \mathrm{mmol}^{\mathrm{m}} \mathrm{PbBr}_{2}, 0.16 \mathrm{mmol}$ of $\mathrm{MABr}$, $20 \mu \mathrm{L}$ of oleylamine and $500 \mu \mathrm{L}$ of oleic acid in dimethylformamide were added to $10 \mathrm{~mL}$ toluene at room temperature to produce a colloidal solution."

The Royal Society of Chemistry apologises for these errors and any consequent inconvenience to authors and readers.

\footnotetext{
${ }^{a}$ Department of Electrical \& Electronic Engineering, Southern University of Science and Technology, Shenzhen, 518055, China. E-mail: chensm@sustc.edu.cn

${ }^{b}$ School of Power and Mechanical Engineering, Wuhan University, Wuhan, 430072, China

${ }^{c}$ Tianjin Key Laboratory of Low Dimensional Materials Physics and Preparing Technology, School of Science, Tianjin University, Tianjin 300072, China

${ }^{d}$ School of Electrical \& Electronic Engineering, Nanyang Technological University, 50 Nanyang Avenue, 639798, Singapore
} 